\title{
Use of Practice-Based Research Network Data to Measure Neighborhood Smoking Prevalence
}

Jeffrey A. Linder, MD, MPH; Nancy A. Rigotti, MD; Phyllis Brawarsky, MPH; Emily Z. Kontos, ScD; Elyse R. Park, PhD, MPH; Elissa V. Klinger; Lucas Marinacci; Wenjun Li, PhD; Jennifer S. Haas, MD, MSPH

Suggested citation for this article: Linder JA, Rigotti NA, Brawarsky P, Kontos EZ, Park ER, Klinger EV, et al. Use of Practice-Based Research Network Data to Measure Neighborhood Smoking Prevalence. Prev Chronic Dis 2013;10:120132. DOI: http://dx.doi.org/10.5888/pcd10.120132 \$.

PEER REVIEWED

\section{Abstract}

\section{Introduction}

Practice-Based Research Networks (PBRNs) and health systems may provide timely, reliable data to guide the development and distribution of public health resources to promote healthy behaviors, such as quitting smoking. The objective of this study was to determine if PBRN data could be used to make neighborhood-level estimates of smoking prevalence.

\section{Methods}

We estimated the smoking prevalence in 32 greater Boston neighborhoods (population $=877,943$ adults) by using the electronic health record data of adults who in 2009 visited one of 26 Partners Primary Care PBRN practices $(\mathrm{n}=$ 77,529). We compared PBRN-derived estimates to population-based estimates derived from 1999-2009 Behavioral Risk Factor Surveillance System (BRFSS) data $(n=20,475)$.

\section{Results}

The PBRN estimates of neighborhood smoking status ranged from $5 \%$ to $22 \%$ and averaged $11 \%$. The 2009 neighborhood-level smoking prevalence estimates derived from the BRFSS ranged from $5 \%$ to $26 \%$ and averaged $13 \%$. The difference in smoking prevalence between the PBRN and the BRFSS averaged -2 percentage points (standard deviation, 3 percentage points).

\section{Conclusion}

Health behavior data collected during routine clinical care by PBRNs and health systems could supplement or be an alternative to using traditional sources of public health data.

\section{Introduction}

Population distribution measurements of health indicators for chronic diseases can be used to target health care and community resources to areas with greatest need. The Centers for Disease Control and Prevention (CDC) and state health departments expend time, money, and energy measuring the distribution of health conditions and behavioral risk factors throughout the United States. The Behavioral Risk Factor Surveillance System (BRFSS), a cornerstone of these efforts with an annual budget of about \$15 million, collects data on smoking, weight, diet, exercise, preventive medical care, and other behaviors $(1,2)$. However, the BRFSS was designed to provide stable estimates at the metropolitan and state levels; because of limited sample sizes, creating stable estimates at the neighborhood level requires complex modeling and pooling several years of data (3).

Practice-based research networks (PBRNs) and integrated health delivery systems also collect patient behavioral health data in the course of routine clinical care $(4,5)$. With increasing use of electronic health records (EHRs), behavioral data are more commonly available in standard formats (6). Data from larger health systems and PBRNs 
could provide a complementary or alternative method of monitoring neighborhood-level prevalence of behavioral risk factors.

Tobacco use remains the leading cause of preventable death in the United States (7). Knowledge about neighborhoodlevel smoking prevalence is necessary to guide the efficient deployment of community-based resources. Patient smoking status is routinely recorded in EHRs; EHR data derived from PBRNs and health systems may provide accurate community-level estimates of the prevalence of tobacco use. To determine if PBRN data could be used to make reasonable neighborhood-level estimates of smoking prevalence, we compared PBRN data to population-based, neighborhood-level estimates of smoking prevalence derived from the BRFSS.

\section{Methods}

\section{Overview}

Our analysis focused on 32 neighborhoods in the greater Boston area that corresponded to the catchment area of the Partners Primary Care PBRN. We compared population-based smoking prevalence estimates derived from the BRFSS and the US Census with 2009 prevalence estimates derived from the Partners Primary Care PBRN. We limited our analysis to respondents and patients aged 18 years or older. The Partners Human Research Committee approved the study protocol.

\section{Data extraction and data analysis}

Three population-based smoking prevalence estimates

We derived individual-level data for population-based smoking prevalence estimates from the BRFSS, a populationbased telephone survey administered by the CDC and state health departments (1). The BRFSS was designed for statewide or metropolitan area use and has been a primary source of population-based information on the prevalence of smoking. As part of the random-digit-dial survey, the BRFSS asks respondents, "Have you smoked 100 cigarettes in your lifetime?" and, if yes, "Do you currently smoke cigarettes?” We included annual population-based data from 1999 through 2009 for respondents who were at least 18 years old and living in 1 of the 32 neighborhoods in the Partners Primary Care PBRN catchment area, based on census tracts. The response rate for the BRFSS in Massachusetts in 2009 was $48 \%$. Community-level data were derived from the 2000 Census.

We combined individual-level data from the BRFSS and community-level data from the US Census to estimate community-level smoking prevalence using a mixed-effects logistic regression model described previously (3). To summarize, using data from 1999 to 2009, the model predicted the prevalence of smoking in each of the 32 five-digit zip code levels in 2009. The model included 7 individual-level characteristics (age, sex, race/ethnicity, marital status, education level, employment, and annual household income), 8 community-level characteristics (median per capita income, percentage of owner-occupied housing units, percentage of blue-collar jobs in the total employed labor force, racial diversity, percentage of vacant housing units, percentage of population in rural area, crude rate of admission to Department of Public Health-funded substance abuse treatment programs, and density of tobacco outlets [number measured per mile of road]), and the year of interview.

Three PBRN-based smoking prevalence estimates

The Partners Primary Care PBRN includes 23 practices in eastern Massachusetts affiliated with Brigham and Women's Hospital or Massachusetts General Hospital. The 23 practices include 5 hospital-based practices, 12 community-based practices, and 6 community health centers. We included patients aged at least 18 who made at least 1 visit to 1 of these PBRN practices in 2009 and had a zip code in 1 of the 32 neighborhoods in the catchment area of the PBRN. The

Partners Primary Care PBRN practices use the Longitudinal Medical Record, an internally developed, web-based, fully functional EHR (8). We assessed smoking status using the EHR patient problem list and the health monitoring module, which contains concepts about health behaviors, prevention, and chronic disease monitoring. Information is entered into the problem list and health monitoring module by various members of the health care team.

We calculated the practice-based smoking prevalence and the frequency with which smoking status was not documented. We calculated the "market share" of the Partners Primary Care PBRN in each of the 32 neighborhoods by dividing the number of PBRN patients by the US Census population 18 years or older in that neighborhood.

We estimated neighborhood smoking prevalence in 2 ways using PBRN data. First, we calculated the crude prevalence of smoking in the PBRN data in each neighborhood by dividing the number of smokers by the total number of patients - smokers, nonsmokers, and patients with undocumented smoking status - from that neighborhood. Second, we calculated the smoking prevalence standardized by the neighborhood makeup according to the 2000 US census using age in 4 categories $(18-39,40-59,60-79$, or $\geq 80$ ), sex, and race/ethnicity in 4 categories (white, Latino, black, or other). There were no patients in 71 of 1,024 cells. To make standardized estimates for these cells, we calculated predicted probabilities using a logistic regression model with smoking as the outcome and 2-way and 3-way interactions between age, sex, and race/ethnicity. We then filled the empty cells by calculating a smoothed estimate of 
the smoking prevalence by fitting the same logistic regression model but leaving out the 3 -way interaction term for that cell.

\section{Statistical analysis}

For BRFSS data, we calculated 95\% confidence intervals using the variances of the random effects from the logistic regression model. For the PBRN data, we calculated exact binomial 95\% confidence intervals. Because of the large sample sizes and our interest in how similar the prevalence of smoking was, we relied on clinical significance rather than formal statistical testing. For ease of interpretation and because smaller increments are unlikely to be clinically significant and may give a false sense of precision, we rounded all proportions to the nearest whole percentage. We assessed the relationship between the practice at which patients were seen and the neighborhood in which they lived using Cramer's $V$. We considered a Cramer's $V$, which can range from o to 1, of 0.25 or higher a strong relationship (9). We used ArcMap 10.o (ESRI, Redlands, California) to generate maps, Stata 11.o (StataCorp, LP, College Station, Texas) to obtain BRFSS population-based estimates, and SAS 9.2 (SAS Institute Inc, Cary, North Carolina) to calculate PBRN-based estimates.

\section{Results}

\section{Sample sizes and characteristics}

According to the US Census, 877,943 adults lived in the 32 neighborhoods in 2009 (population range across neighborhoods, 4,143-60,028). From 1999 to 2009, there were 20,475 adult BRFSS respondents who lived in the target area of interest used to estimate 2009 smoking prevalence (sample range across neighborhoods, 85-1,731).

There were 77,516 adult patients seen in the Partners Primary Care PBRN in 2009 who lived in 1 of the 32 neighborhoods (range across neighborhoods, 430-7,960). There was a strong relationship between the practice patients attended and neighborhood in which they lived (Cramer's $V$, o.33). Compared with census-determined characteristics, adults seen in Partners PBRN practices were more likely to be older, female, and Latino (Table 1).

\section{Practice-based smoking documentation}

Overall, $12 \%$ of patients seen at the Partners PBRN practices were documented smokers and $27 \%$ did not have smoking status documented. Across the 23 practices, the documented smoking rate averaged $11 \%$ (range, $4 \%-24 \%$ ). The proportion of patients without smoking status documented across the 23 practices averaged $27 \%$ (range, $1 \%-79 \%$ ).

\section{Neighborhood smoking prevalence}

According to the BRFSS, smoking prevalence averaged 13\%, ranging from $5 \%$ to $26 \%$ (Table 2, Figure 1). Partners PBRN practices had a market share among adults in the 32 communities that averaged $10 \%$, ranging from $3 \%$ to $32 \%$ (Table 2). Standardizing data according to the demographic makeup of a community resulted in modest changes in the estimated smoking prevalence: rates were higher in 16 neighborhoods, lower in 5 neighborhoods, and the same in 11 neighborhoods. The overall prevalence averaged among neighborhoods remained $11 \%$ (range, $5 \%-22 \%$ ). 


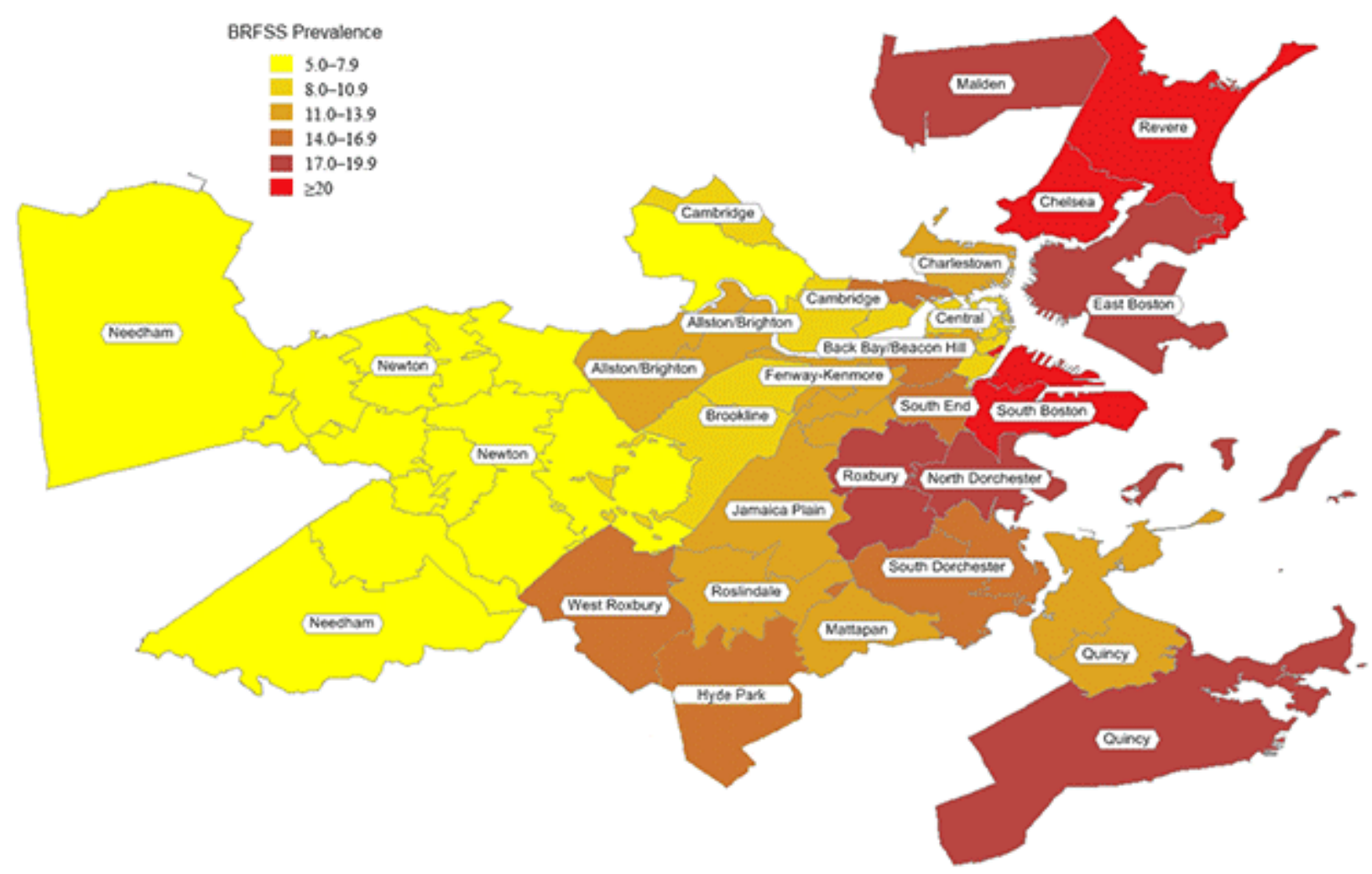

Figure 1. Population-based smoking prevalence in 32 Boston neighborhoods. Data derived from the Behavioral Risk Factor Surveillance System, 1999-2009. [A tabular version of this figure is also available.]

According to standardized PBRN data, the 32 neighborhoods had an overall smoking prevalence of $11 \%$, ranging from $5 \%$ to 22\% (Table 2, Figure 2). Compared with BRFSS estimates, the standardized PBRN estimates averaged 2 percentage points lower (standard deviation, 3 percentage points), and the differences ranged from -10 percentage points (South Boston; 11\% PBRN prevalence and 21\% BRFSS prevalence; 7\% PBRN market share) to +6 percentage points (Charlestown; 18\% PBRN prevalence and 12\% BRFSS prevalence; 32\% PBRN market share with a neighborhood Community Health Center). The PBRN estimates were lower by more than 5 percentage points in 5 neighborhoods (Table 2, Figure 3). 


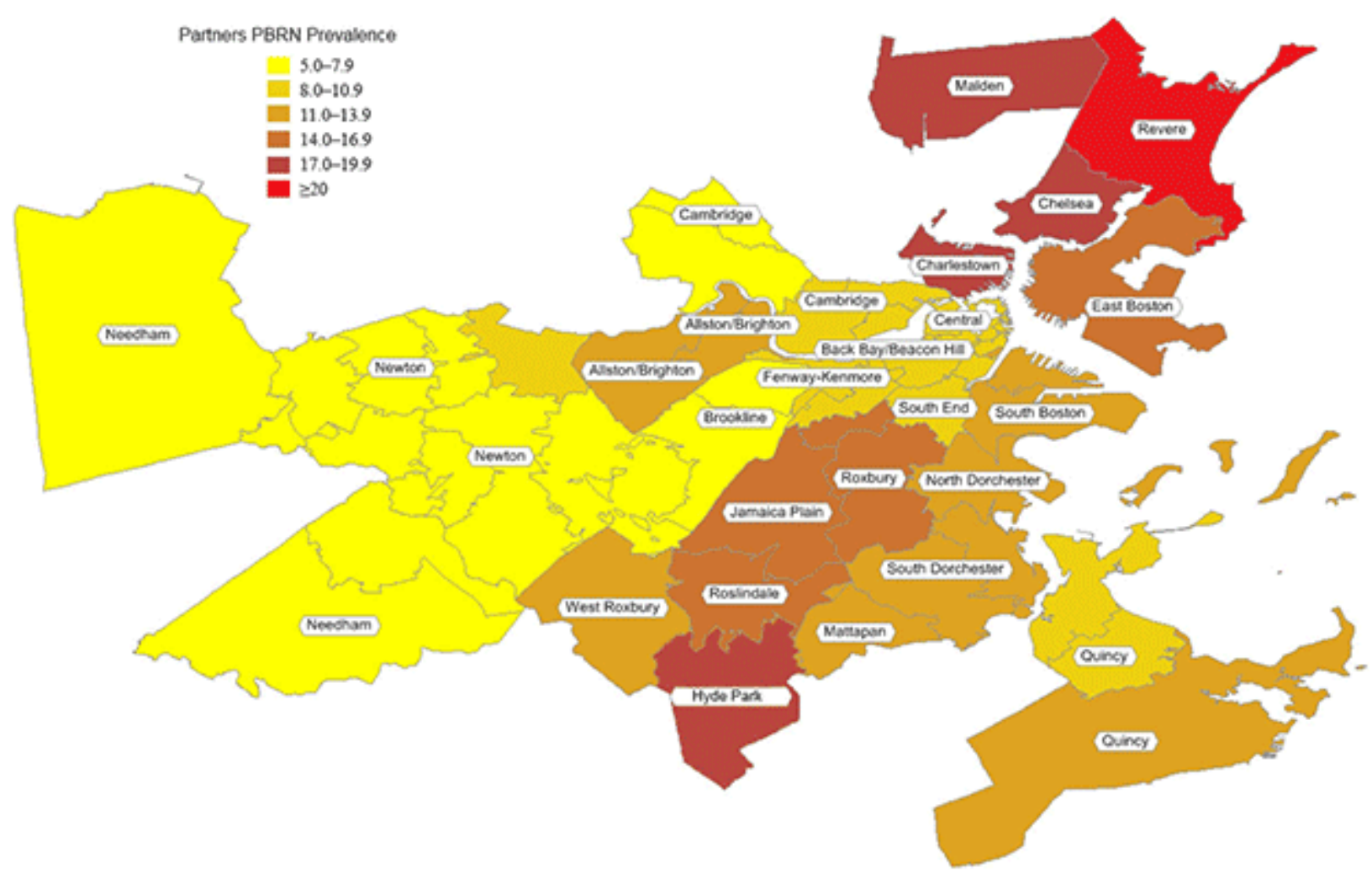

Figure 2. Practice-Based Research Network smoking prevalence in 32 Boston Neighborhoods. [A tabular version of this figure is also available.]

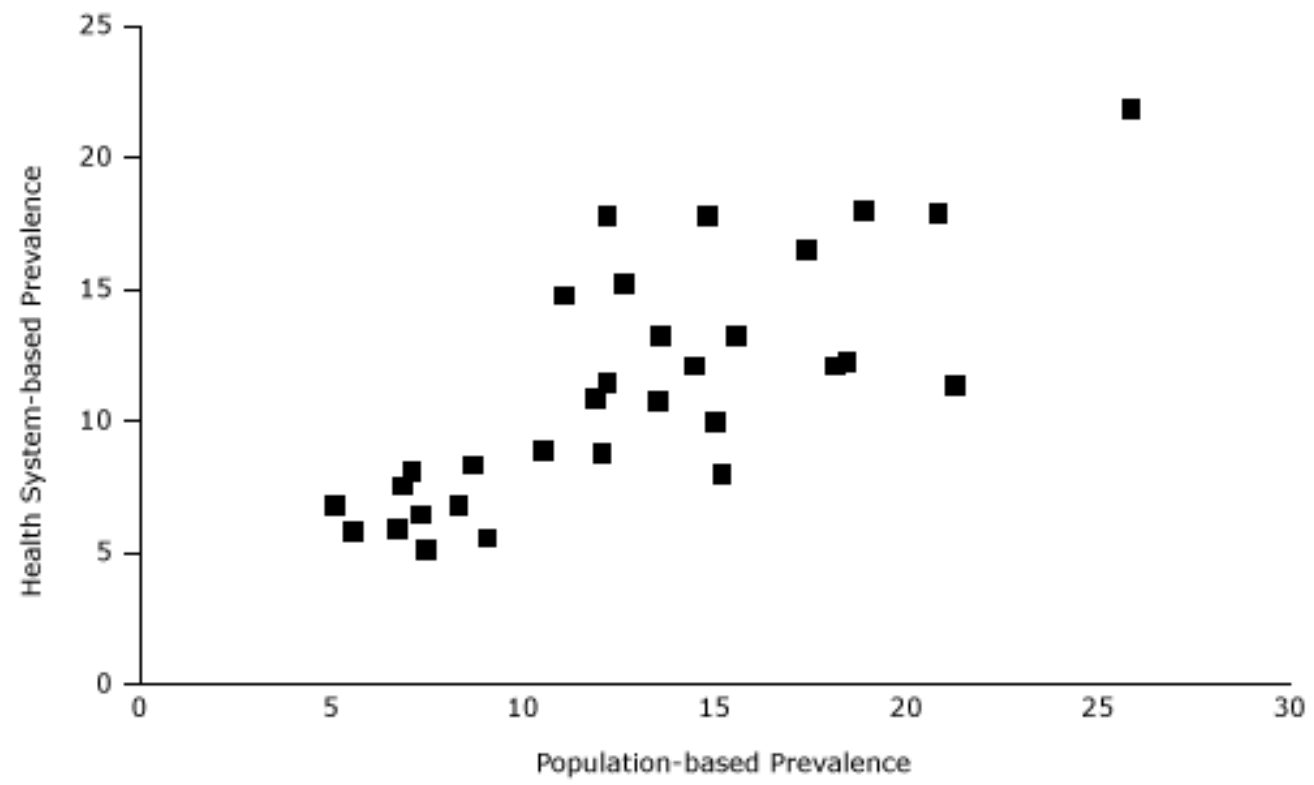

Figure 3. Scatter plot of Practice-Based Research Network (PBRN) smoking prevalence and population-based neighborhood prevalence of smoking for 32 Boston neighborhoods (\%). [A tabular version of this figure is also available.]

\section{Discussion}

Neighborhood-level smoking prevalence can be estimated using EHR data from a PBRN, collected in the routine course of clinical care. Generally, PBRN estimates were slightly lower than the BRFSS estimates, but they were higher in some neighborhoods in which the PBRN had higher market penetration. 
PBRN smoking prevalence estimates may have been generally lower for several reasons. Practices did not have smoking status documented for $100 \%$ of patients. Though not directly comparable, our $73 \%$ documentation rate compares favorably to the BRFSS response rate of $48 \%$, a rate that is declining (10). In addition, clinicians preferentially document the smoking status of smokers. Efforts to increase smoking status documentation, including local and national incentives and EHR reminders, preferentially add nonsmokers, leading to small changes in the measured smoking prevalence. Our previous intervention to increase smoking status documentation served to increase the rate of documentation only for patients who were former smokers and never smokers; there was no significant change in the proportion of documented smokers (11). The discrepancies between PBRN and BRFSS estimates may also be attributable to the differential coverage of the populations by PBRN and BRFSS. Also, our PBRN patient population differs from the greater Boston area adult population, the sampling frame for the BRFSS, by having a lower percentage of Medicaid beneficiaries, more women than men, and likely healthier or more health-conscious patients (12).

Other studies have noted similarities and differences between health system-based and population-based estimates of smoking prevalence. A study in Leicester, England, found that General Practice notes, computerized and manual, tended to overestimate population smoking prevalence (13). On a larger scale in the UK, a comparison of an EHRbased PBRN, containing approximately $6 \%$ of the UK population, to the population-based General Lifestyle Survey showed excellent agreement both nationally and regionally $(14,15)$. However, this analysis is not geographically granular enough to allow targeting of neighborhood resources. In the United States, commercial EHRs with broad national penetration may have greater potential to make regional and national estimates of acute and chronic conditions, as well as behavioral risk factors (16).

Using PBRN or health system data to measure the neighborhood prevalence of smoking offers several advantages over traditional, population-based methods. First, the data are already collected as part of routine clinical care, so their collection is less expensive than using a separate infrastructure to conduct population-based surveys. Second, for small -area estimation, as our data show, the sample sizes available in PBRN data are much larger, resulting in smaller standard errors (although relative to neighborhood population, even the PBRN estimates might be considered small), which may allow for the targeting of community-based interventions in smaller areas than is feasible using the BRFSS. Third, given the larger sample size and collection during routine clinical care, the data are potentially more current than population-based surveys, for which time is needed for data to become available (14). Fourth, because data were taken from an EHR, the potential exists for smoking status to be linked to a richer data set consisting of other behaviors, comorbidities, medications, and health outcomes for varied patients (17). Similarly, EHR-based measurements can be linked with practice-based treatment interventions $(\mathbf{1 1}, 18-20)$. Finally, the emergence and implementation of EHR data standards as part of the national Meaningful Use EHR Incentive program will allow for information pooling across multiple health systems and encourage routine documentation of smoking status as it did for the General Practice pay-for-performance contract in Britain (21). Some of the inherent data problems associated with market share of this single PBRN could be resolved by pooling data from multiple health systems.

Despite these advantages to PBRN and health system data, advantages exist to population-based estimates, such as those derived from BRFSS. Obviously, despite low and declining response rates, the BRFSS is population-based and can provide estimates regardless of whether an individual seeks care through a particular health system or seeks health care at all. The BRFSS is not dependent on "market share" to get more accurate estimates, is not dependent on the presence of health care facilities in neighborhoods, and is not subject to health system peculiarities that may limit the generalizability of PBRN data. Second, although it was not intended to provide the small-scale prevalence we calculated, the BRFSS is consistently administered across the United States. Third, the BRFSS potentially provides greater consistency over time. Although standards are emerging for the structure of EHR data, the BRFSS data are collected with greater attention to consistency in definitions and measurement. Population-based surveys are not free from bias, however. For example, smokers generally have lower response rates to surveys than do nonsmokers (13). Finally, patients may be more likely to report negative health behaviors like smoking to health care providers than via a population survey.

Our analysis suggests that PBRNs and health system data can be used to guide community resources to neighborhoods with greater need. However, an understanding of the limitations of estimates derived from nonpopulation-based sources, for example, data from a single health system with low market penetration, cannot be used for small-area estimation, because the results are potentially biased because of insufficient population coverage and selection bias.

The true public health benefit of using health system-based risk factor information will come from combining data from multiple health systems, which requires a change in view of health system data as a public health resource. A convergence of health system data with population-based results should be seen more often as documentation improves (14). Health system data could be part of a systematic surveillance system that would help in understanding the effectiveness of tobacco control programs (22), particularly with mandated reporting of behavioral risk factors such as tobacco use, obesity, alcohol use, and others (23). Such a system could afford greater opportunity for collaboration and synergy between health care systems, public health departments, community organizations, and other community 
-based resources. In effect, this may encourage the surrounding community to take a greater stake in the health system and the health system to take a greater stake in the surrounding community.

\section{Acknowledgments}

This work was conducted with support from The Lung Cancer Disparities Center at the Harvard School of Public Health (National Cancer Institute Award no. P50 CA148596) and the Harvard Catalyst, the Harvard Clinical and Translational Science Center (NIH Grant no. 1 UL1 RR 025758-01 and financial contributions from participating institutions). The content is solely the responsibility of the authors and does not necessarily represent the official views of Harvard University and its affiliated academic health care centers or the National Institutes of Health.

\section{Author Information}

Corresponding Author: Jennifer S. Haas, MD, MSPH, Division of General Medicine and Primary Care, Brigham and Women's Hospital, 1620 Tremont St, Boston, MA 02120. Telephone: 617-525-6652. E-mail: jhaas@partners.org. Dr Haas is also affiliated with Harvard Medical School, Boston, Massachusetts.

Author Affiliations: Jeffrey A. Linder, Division of General Medicine and Primary Care, Brigham and Women's Hospital, and Harvard Medical School, Boston, Massachusetts; Phyllis Brawarsky, Division of General Medicine and Primary Care, Brigham and Women's Hospital, Boston, Massachusetts; Nancy A. Rigotti, Tobacco Research and Treatment Center and General Medicine Division, Massachusetts General Hospital, and Harvard Medical School, Boston, Massachusetts; Elyse R. Park, Tobacco Research and Treatment Center and General Medicine Division, Massachusetts General Hospital, and Harvard Medical School, Boston, Massachusetts; Emily Z. Kontos, Department of Society, Human Development and Health, Harvard School of Public Health, Boston, Massachusetts; Wenjun Li, Division of Preventive and Behavioral Medicine, University of Massachusetts Medical School, Boston, Massachusetts.

\section{References}

1. Office of Surveillance, Epidemiology, and Laboratory Services. Behavioral Risk Factor Surveillance System. Atlanta (GA): Centers for Disease Control and Prevention; 2011.

2. Anderson RN. United States life tables, 1998. Natl Vital Stat Rep 2001;48(18):1-40. PubMed 芯

3. Li W, Land T, Zhang Z, Keithly L, Kelsey JL. Small-area estimation and prioritizing communities for tobacco control efforts in Massachusetts. Am J Public Health 2009;99(3):470-9. CrossRef 通 PubMed 芯

4. Lindbloom EJ, Ewigman BG, Hickner JM. Practice-based research networks: the laboratories of primary care research. Med Care 2004;42(4, Suppl):III45-9. PubMed 㝕

5. Westfall JM, Mold J, Fagnan L. Practice-based research - "Blue Highways" on the NIH roadmap. JAMA 2007;297(4):403-6. CrossRef 虑 PubMed 店

6. Blumenthal D, Tavenner M. The "meaningful use" regulation for electronic health records. N Engl J Med 2010;363(6):501-4. CrossRef 虔 PubMed 密

7. Fiore MC, Jaen CR, Baker TB, Bailey WC, Benowitz NL, Curry SJ, et al. Treating tobacco use and dependence: 2008 update. Clinical practice guideline. Rockville (MD): US Department of Health and Human Services, Public Health Service; 2008.

8. Certification Commission for Healthcare Information Technology. Partners Healthcare System, Partners Longitudinal Medical Record LMR 9.0. 2011.

9. Kendall M, Stuart A. The advanced theory of statistics. New York (NY): Macmillan Publishing Company, Inc; 1979.

10. Hu SS, Pierannunzi C, Balluz L. Integrating a multimode design into a national random-digit-dialed telephone survey. Prev Chronic Dis 2011;8(6):A145. PubMed 虔

11. Linder JA, Rigotti NA, Schneider LI, Kelley JH, Brawarsky P, Haas JS. An electronic health record-based intervention to improve tobacco treatment in primary care: a cluster-randomized controlled trial. Arch Intern Med 2009;169(8):781-7. CrossRef 虑 PubMed 图

12. Land T, Warner D, Paskowsky M, Cammaerts A, Wetherell L, Kaufmann R, et al. Medicaid coverage for tobacco dependence treatments in Massachusetts and associated decreases in smoking prevalence. PLoS ONE 2010;5 (3):e9770. CrossRef 远 PubMed 实

13. Wilson A, Manku-Scott T, Shepherd D, Jones B. A comparison of individual and population smoking data from a postal survey and general practice records. Br J Gen Pract 2000;50(455):465-8. PubMed 图

14. Szatkowski L, Lewis S, McNeill A, Huang Y, Coleman T. Can data from primary care medical records be used to monitor national smoking prevalence? J Epidemiol Community Health 2012;66(9):791-5. PubMed w 
Preventing Chronic Disease I Use of Practice-Based Research Network Data to Measure ... Page 8 of 10

15. Langley TE, Szatkowski LC, Wythe S, Lewis SA. Can primary care data be used to monitor regional smoking prevalence? An analysis of The Health Improvement Network primary care data. BMC Public Health 2011;11:773. CrossRef 通 PubMed 还

16. Crawford AG, Cote C, Couto J, Daskiran M, Gunnarsson C, Haas K, et al. Comparison of GE Centricity Electronic Medical Record database and National Ambulatory Medical Care Survey findings on the prevalence of major conditions in the United States. Popul Health Manag 2010;13(3):139-50. CrossRef i $^{2}$ PubMed i

17. Solberg LI, Flottemesch TJ, Foldes SS, Molitor BA, Walker PF, Crain AL. Tobacco-use prevalence in special populations taking advantage of electronic medical records. Am J Prev Med 2008;35(6, Suppl):S501-7. CrossRef 迹 PubMed 迹

18. Lindholm C, Adsit R, Bain P, Reber PM, Brein T, Redmond L, et al. A demonstration project for using the electronic health record to identify and treat tobacco users. WMJ 2010;109(6):335-40. PubMed

19. Boyle RG, Solberg LI, Fiore MC. Electronic medical records to increase the clinical treatment of tobacco dependence: a systematic review. Am J Prev Med 2010;39(6, Suppl 1):S77-82. CrossRef 虑 PubMed 通

20. Boyle R, Solberg LI, Fiore MC. Use of electronic health records to support smoking cessation. Cochrane Database Syst Rev 2011;12:CDoo8743. . CrossRef 兽 PubMed 图

21. Coleman T, Lewis S, Hubbard R, Smith C. Impact of contractual financial incentives on the ascertainment and management of smoking in primary care. Addiction 2007;102(5):803-8. CrossRef 虑 PubMed 图

22. Farrelly MC. Monitoring the tobacco use epidemic V: the environment: factors that influence tobacco use. Prev Med 2009;48(1, Suppl):S35-43. CrossRef 图 PubMed 必

23. Li W, Kelsey JL, Zhang Z, Lemon SC, Mezgebu S, Boddie-Willis C, et al. Small-area estimation and prioritizing communities for obesity control in Massachusetts. Am J Public Health 2009;99(3):511-9. CrossRef 图 PubMed 虔

\section{Tables}

Table 1. Patient Characteristics Derived From Population-Based Data and Practice-Based Research Network Data, 32 Neighborhoods in Boston, Massachusetts

\begin{tabular}{|c|c|c|}
\hline \multirow[b]{2}{*}{ Characteristic } & \multicolumn{2}{|r|}{ Practice-Based Research Network } \\
\hline & \multicolumn{2}{|r|}{ N (\%) } \\
\hline Total & $877,943(100)$ & $77,516(100)$ \\
\hline \multicolumn{3}{|l|}{ Age, y } \\
\hline $18-39$ & $457,634(52)$ & $27,629(36)$ \\
\hline $40-59$ & $253,104(29)$ & $28,705(37)$ \\
\hline $60-79$ & $128,800(15)$ & $17,074(22)$ \\
\hline$\geq 80$ & $38,405(4)$ & $4,108(5)$ \\
\hline \multicolumn{3}{|l|}{ Sex } \\
\hline Female & $463,807(53)$ & $47,831(62)$ \\
\hline Male & $414,136(47)$ & $29,685(38)$ \\
\hline \multicolumn{3}{|l|}{ Race/ethnicity } \\
\hline White & $570,879(65)$ & $44,877(58)$ \\
\hline Black & $114,940(13)$ & $8,449(11)$ \\
\hline Latino & $83,701(10)$ & $15,272(20)$ \\
\hline Other & $108,423(12)$ & $8,918(12)$ \\
\hline \multicolumn{3}{|l|}{ Language } \\
\hline English & $712,249(69)^{a}$ & $63,463(82)$ \\
\hline Spanish & $108,275(10)^{a}$ & $9,401(12)$ \\
\hline
\end{tabular}


Preventing Chronic Disease I Use of Practice-Based Research Network Data to Measure ... Page 9 of 10

\begin{tabular}{|l|c|c|}
\hline \multirow{2}{*}{ Characteristic } & 2000 Census & \multicolumn{2}{|c|}{ Practice-Based Research Network } \\
\cline { 2 - 3 } & \multicolumn{2}{|c|}{ N (\%) } \\
\hline Other & $212,334(21)^{\mathrm{a}}$ & \\
\hline
\end{tabular}

a Language was available for the census only for the population age 5 or older. Total $\mathrm{N}$ for census language data was $1,032,858$.

Table 2. Smoking Prevalence Estimated From the Behavioral Risk Factor Surveillance System and the Partners Primary Care Practice-Based Research Network, 32 Neighborhoods in Boston, Massachusetts

\begin{tabular}{|c|c|c|c|c|c|c|c|c|}
\hline \multirow[b]{2}{*}{$\begin{array}{l}\text { Community } \\
\text { Namea }^{\text {a }}\end{array}$} & \multirow[b]{2}{*}{$\begin{array}{c}\text { Adult } \\
\text { Populationb }\end{array}$} & \multicolumn{2}{|c|}{$\begin{array}{c}\text { Population-Based } \\
\text { Estimates }\end{array}$} & \multicolumn{4}{|c|}{ Practice-Based Research Network } & \multirow{2}{*}{$\begin{array}{c}\text { Percentage } \\
\text { Point } \\
\text { Difference i } \\
\text { Standardize } \\
\text { Population } \\
\text { Estimates }\end{array}$} \\
\hline & & $\begin{array}{c}N \\
(1999 \\
\text { to } \\
2009)\end{array}$ & $\begin{array}{c}\text { Smoking } \\
\text { Prevalence, } \\
\%(95 \% \\
\text { CI) }\end{array}$ & $\begin{array}{c}N \\
(2009)\end{array}$ & $\begin{array}{c}\text { Market } \\
\text { Share,d } \\
\%\end{array}$ & $\begin{array}{c}\text { Crude } \\
\text { Smoking } \\
\text { Prevalence,e } \\
\%(95 \% \mathrm{CI})\end{array}$ & $\begin{array}{l}\text { Standardized } \\
\text { Smoking } \\
\text { Prevalence, } \\
\%(95 \% \mathrm{CI})\end{array}$ & \\
\hline South Boston & 24,569 & 872 & $21(19-24)$ & 1,723 & 7 & $12(10-13)$ & $11(9-13)$ & -1 \\
\hline $\begin{array}{l}\text { Cambridge } \\
(141)\end{array}$ & 10,204 & 85 & $15(13-18)$ & 495 & 5 & $8(6-10)$ & $8(5-11)$ & - \\
\hline Quincy (169) & 42,855 & 536 & $19(16-21)$ & 1,190 & 3 & $12(10-14)$ & $12(10-15)$ & - \\
\hline $\begin{array}{l}\text { North } \\
\text { Dorchester }\end{array}$ & 24,343 & 686 & $18(16-21)$ & 1,257 & 5 & $13(11-15)$ & $12(10-14)$ & - \\
\hline South End & 37,451 & 1,310 & $15(14-17)$ & 3,009 & 8 & $10(9-11)$ & $10(9-11)$ & - \\
\hline Revere & 37,363 & 426 & $26(23-29)$ & 7,960 & 21 & $20(19-21)$ & $22(21-23)$ & - \\
\hline $\begin{array}{l}\text { Cambridge } \\
(140)\end{array}$ & 13,907 & 218 & $9(8-11)$ & 638 & 5 & $5(3-7)$ & $6(4-8)$ & - \\
\hline $\begin{array}{l}\text { Back } \\
\text { Bay/Beacon Hill }\end{array}$ & 4143 & 394 & $12(10-14)$ & 714 & 17 & $8(6-10)$ & $9(7-11)$ & - \\
\hline Chelsea & 25,512 & 276 & $21(18-24)$ & 6,113 & 24 & $15(14-15)$ & $18(16-20)$ & - \\
\hline $\begin{array}{l}\text { Quincy } \\
(170 / 171)\end{array}$ & 29,789 & 336 & $14(12-16)$ & 970 & 3 & $10(9-12)$ & $11(8-13)$ & - \\
\hline Needham & 29,589 & 389 & $8(6-9)$ & 2,393 & 8 & $5(4-6)$ & $5(4-6)$ & - \\
\hline West Roxbury & 19,741 & 911 & $15(13-16)$ & 3,126 & 16 & $11(10-12)$ & $12(10-14)$ & - \\
\hline $\begin{array}{l}\text { South } \\
\text { Dorchester }\end{array}$ & 53,044 & 1,731 & $16(14-17)$ & 2,768 & 5 & $13(12-14)$ & $13(12-15)$ & - \\
\hline Brookline & 46,737 & 799 & $8(7-10)$ & 3,949 & 8 & $6(6-7)$ & $7(6-8)$ & - \\
\hline $\begin{array}{l}\text { Cambridge } \\
(139 / 142)\end{array}$ & 31,839 & 406 & $11(9-12)$ & 1,457 & 5 & $8(7-10)$ & $9(7-11)$ & - \\
\hline $\begin{array}{l}\text { Fenway- } \\
\text { Kenmore }\end{array}$ & 45,724 & 776 & $12(11-14)$ & 1,763 & 4 & $11(10-13)$ & $11(9-13)$ & - \\
\hline East Boston & 29,364 & 935 & $17(16-19)$ & 2,182 & 7 & $17(15-19)$ & $16(13-20)$ & - \\
\hline $\begin{array}{l}\text { Cambridge } \\
(138)\end{array}$ & 31,989 & 401 & $7(6-9)$ & 1,124 & 4 & $6(5-7)$ & $6(5-8)$ & - \\
\hline Roxbury & 32,908 & 1,060 & $17(16-19)$ & 3,100 & 9 & $16(15-18)$ & $17(15-18)$ & - \\
\hline Malden & 45,102 & 469 & $19(17-22)$ & 2,471 & 5 & $16(15-17)$ & $18(16-20)$ & - \\
\hline $\begin{array}{l}\text { Newton } \\
(462 / 466)\end{array}$ & 6,834 & 104 & $7(6-8)$ & 430 & 6 & $6(4-8)$ & $6(4-8)$ & - \\
\hline
\end{tabular}


Preventing Chronic Disease I Use of Practice-Based Research Network Data to Measur... Page 10 of 10

\begin{tabular}{|c|c|c|c|c|c|c|c|c|}
\hline \multirow[b]{2}{*}{$\begin{array}{l}\text { Community } \\
\text { Namea }^{a}\end{array}$} & \multirow[b]{2}{*}{$\begin{array}{c}\text { Adult } \\
\text { Populationb }\end{array}$} & \multicolumn{2}{|c|}{$\begin{array}{l}\text { Population-Based } \\
\text { Estimatesc }\end{array}$} & \multicolumn{4}{|c|}{ Practice-Based Research Network } & \multirow{2}{*}{$\begin{array}{c}\text { Percentage } \\
\text { Point } \\
\text { Difference iı } \\
\text { Standardize } \\
\text { Population } \\
\text { Estimates }\end{array}$} \\
\hline & & $\begin{array}{c}\text { N } \\
(1999 \\
\text { to } \\
2009)\end{array}$ & $\begin{array}{c}\text { Smoking } \\
\text { Prevalence, } \\
\%(95 \% \\
\text { CI })\end{array}$ & $\begin{array}{c}\mathbf{N} \\
(2009)\end{array}$ & $\begin{array}{c}\text { Market } \\
\text { Share,d } \\
\%\end{array}$ & $\begin{array}{c}\text { Crude } \\
\text { Smoking } \\
\text { Prevalence,e } \\
\%(95 \% \mathrm{CI})\end{array}$ & $\begin{array}{c}\text { Standardized } \\
\text { Smoking } \\
\text { Prevalence, } \\
\%(95 \% \mathrm{CI})\end{array}$ & \\
\hline Allston/Brighton & 60,028 & 1,363 & $12(11-14)$ & 1,968 & 3 & $11(9-12)$ & $11(9-14)$ & - \\
\hline Mattapan & 19,623 & 495 & $14(12-16)$ & 1,335 & 7 & $12(10-14)$ & $13(9-17)$ & \\
\hline Central Boston & 19,332 & 677 & $9(8-10)$ & 2,547 & 13 & $9(8-10)$ & $8(7-10)$ & \\
\hline $\begin{array}{l}\text { Newton } \\
(459 / 467)\end{array}$ & 23,042 & 536 & $6(5-7)$ & 3,274 & 14 & $5(4-6)$ & $6(5-7)$ & \\
\hline $\begin{array}{l}\text { Newton } \\
(460 / 465)\end{array}$ & 15,927 & 289 & $7(6-8)$ & 1,281 & 8 & $6(5-8)$ & $8(5-10)$ & \\
\hline Newton (458) & 9,783 & 148 & $7(6-9)$ & 1,019 & 10 & $8(6-9)$ & $8(6-11)$ & \\
\hline $\begin{array}{l}\text { Newton } \\
(461 / 464 / 468)\end{array}$ & 11,299 & 223 & $5(4-6)$ & 1,036 & 9 & $7(5-8)$ & $7(5-9)$ & \\
\hline Roslindale & 24,474 & 905 & $13(11-14)$ & 3,375 & 14 & $14(13-15)$ & $15(14-17)$ & \\
\hline Hyde Park & 20,911 & 774 & $15(13-17)$ & 3,182 & 15 & $15(14-16)$ & $18(16-20)$ & \\
\hline Jamaica Plain & 38,146 & 1,402 & $11(10-13)$ & 5,665 & 15 & $14(13-15)$ & $15(13-16)$ & \\
\hline Charlestown & 12,371 & 543 & $12(11-14)$ & 4,015 & 32 & $19(17-20)$ & $18(16-20)$ & \\
\hline $\begin{array}{l}\text { Total or } \\
\text { average }\end{array}$ & 877,943 & 20,475 & 13 & 77,529 & 10 & 11 & 11 & - \\
\hline
\end{tabular}

Abbreviation: CI, confidence interval.

a Numbers following community names represent zip codes, which have a leading "02" omitted.

b Adult population estimates derived from the 2000 US Census.

c Population-based estimates derived from the Behavioral Risk Factor Surveillance System.

d Market share was calculated by dividing the number of Practice-Based Research Network patients by the census population aged 18 years or older in that neighborhood.

e Crude smoking prevalence was calculated by dividing the number of smokers by the total number of patients in each neighborhood.

f Standardized smoking prevalence was calculated by standardizing the age, sex, and race/ethnicity of Practice Based Research Network patients according to the neighborhood makeup according to the 2000 Census.

The opinions expressed by authors contributing to this journal do not necessarily reflect the opinions of the U.S. Department of Health and Human Services, the Public Health Service, the Centers for Disease Control and Prevention, or the authors' affiliated institutions.

The RIS file format is a text file containing bibliographic citations. These files are best suited for import into

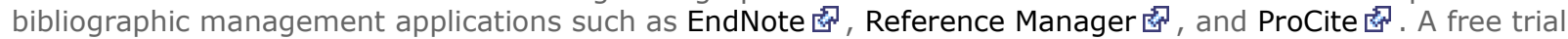
download is available at each application's web site.

For Questions About This Article Contact pcdeditor@cdc.gov

Page last reviewed: May 23, 2013

Page last updated: May 23, 2013

Content source: National Center for Chronic Disease Prevention and Health Promotion

Centers for Disease Control and Prevention 1600 Clifton Rd. Atlanta, GA 30333, USA

80o-CDC-INFO (800-232-4636) TTY: (888) 232-6348 - Contact CDC-INFO 